\title{
ANALISIS KRITIK SOSIAL KEPADA KONTRAKTOR DAN MASYARAKAT DALAM PUISI ESAI “ABORSI DI PALIPPIS" KARYA SYUMAN SAEHA
}

\author{
Naim Irmayani ${ }^{*}$, Andriani ${ }^{1}$ \\ IUniversitas Al Asyariah Mandar \\ *Email: naimirmayanicomel27@gmail.com
}

\begin{abstract}
This research is motivated by how the social criticism contained in the poetry essay "Abortion in Palippis" by Syuman Saeha. The purpose of this research is to find out the social criticism in Syuman Saeha's essay "Abortion in Palippis". The method used in this study is a qualitative descriptive method to describe data in the form of mental elements and social criticism in the poem essay "Abortion di Palippis". Shuman Saeha's work. The research technique used is document analysis, namely the poetry essay "Abortion di Palippis" by Syuman Saeha and interviewing the resource person, Syuman Saeha, as the poet of the essay "Abortion di Palippis". The research results obtained were the inner elements of the essay poetry "Abortion di Palippis" consisting of theme, taste, tone of atmosphere and message. The social criticism obtained is in the form of criticism against the government, contractors and the community. Social criticism of the government has 4 points, against contractors 3 points and against society 3 points. Of the three targets of criticism, the government is seen as the party most responsible for creating social problems as is the social criticism obtained in the poem Shuman Saeha's "Abortion di Palippis" essay.
\end{abstract}

Keywords: analysis, social criticism, essay poetry

\section{PENDAHULUAN}

Sastra sebagai bentuk karya seni tulis yang indah terdiri atas tiga genre yakni puisi, prosa dan drama. Tiga genre tersebut memiliki kekhasan tersendiri yang membuat ketiganya memiliki perbedaan signifikan. Genre puisi memiliki ciri khas yakni dari struktur kata yang digunakan cenderung padat dan namun menghasilkan nilai estetik yang mendalam. Berbeda dengan genre prosa memiliki khas adanya penarasian peristiwa dengan ragam-ragam intrinsik yang membangunnya. Sedangkan genre drama berciri khas adanya penaskahan berupa 
dialog dan penanda gerak serta berkaitan pula dengan seni pertunjukan apabila dipentaskan.

Karya sastra lahir dari latar belakang dan dorongan dasar manusia untuk mengungkapkan eksistensi dirinya. Sebuah karya sastra dipersepsikan sebagai ungkapan realitas kehidupan dan konteks penyajiannya disusun secara terstruktur, menarik, serta menggunakan media bahasa berupa teks yang disusun melalui refleksi pengalaman dan pengetahuan secara potensial memiliki berbagai macam bentuk representasi kehidupan. Demikianlah sebuah karya sastra sehingga menjadi atau dapat melalui kritik oleh pembaca (Willya, 2017: 2).

Secara sederhana, kritik sosial merupakan salah satu bentuk kepekaan sosial. Kritik sosial yang murni tidak didasarkan pada tanggung jawab bahwa manusia bersama-sama bertanggung jawab terhadap lingkungan sosialnya. Oleh karena itu, kritik sosial mencakup berbagai segi kehidupan baik politik, ekonomi, sosial dan budaya. Hal ini sejurus dengan tujuan puisi esai yakni menyampaikan gagasan ataupun tanggapan terhadap fakta sosial yang terjadi di dalam kehidupan. Salah satu gagasan yang dihadirkan lewat puisi esai yaitu kritik sosial. Kritik sosial tersebut misalnya ditujukan terhadap permasalahan sosial yang ada seperti ketidakadilan, penindasan dan lainnya yang benar-benar terjadi di kehidupan kita.

Darmayanti (2014:487) juga membahas tentang kritik sastra, peristiwaperistiwa kekerasan terhadap seksualitas perempuan mengilhami pengarang dalam karya sastranya. Hal ini tidak terlepas dari pandangan bahwa karya sastra terkonstruksi tidak dari kekosongan belaka, tetapi dari peristiwa-peristiwa di sekitar kehidupan pengarang. Ini adalah konsep teori mimesis. Karya sastra sebagai peniruan dari peristiwa yang terjadi di masyarakat.

Amalia (2006:1) menjelaskan tentang kritik sosial yang berupa sindiran, tanggapan, yang ditujukan pada suatu hal yang terjadi dalam masyarakat manakala terdapat sebuah konfrontasi dengan realitas berupa kepincangan atau kebobrokan. Kritik sosial diangkat ketika kehidupan dinilai tidak selaras dan tidak harmonis, ketika masalah-masalah sosial tidak dapat diatasi dan perubahan sosial mengarah kepada dampak-dampak disosiatif dalam masyarakat. Hal tersebut menandakan bahwa kririk sosial dalam suatu karya merupakan kritik terhadap masalah sosial yang terjadi dalam suatu lingkungan masyarakat. Kepincangan-kepincangan yang dianggap sebagai masalah sosial oleh masyarakat tergantung dari sistem nilai-nilai sosial masyarakat tersebut, akan tetapi ada beberapa persoalan yang sama dihadapi oleh masyarakat pada umumnya, misalnya: masalah kemiskinan, masalah kejahatan, disorganisasi keluarga, masalah generasi muda dalam masyarakat modern, peperangan, pelanggaran terhadap norma-norma masyarakat, masalah kependudukan, masalah lingkungan hidup, dan birokrasi (Pratiwi, 2017:4). 
"Aborsi di Palippis" menunjukkan pembaca mengenai realitas sosial masyarakat yang menetap dan menggantungkan hidup di Pantai Palippis. Oleh karena itu, akan sangat menarik apabila diadakan penelitian lebih mendalam. Kajian yang dianggap relevan untuk meneliti puisi esai "Aborsi di Palippis" karya Syuman Saeha ini adalah dengan menggunakan kritik sosial sastra untuk mengetahui kritik sosial apa saja yang terdapat pada puisi ini. Pendekatan dalam penelitian ini menggunakan pendekatan mimetik untuk melihat bagaimana kaitan karya dengan kenyataan yang pernah ada.

\section{METODE PENELITIAN}

Penelitian ini adalah penelitian deskriptif kualitatif. Deskriptif kualitatif adalah suatu rancangan penelitian yang mendeskripsikan fenomena yang menjadi sasaran penelitian secara alamiah. Alamiah dimaksudkan sebagai fenomena yang menjadi sasaran penelitian dideskripsikan sebagaimana adanya tanpa disertai perlakuan, pengukuran dan perhitungan statistik.

Creswell (2007:02) menjelaskan bahwa kualitatif sebagai sebuah proses penyelidikan untuk memahami masalah sosial atau masalah manusia, berdasarkan penciptaan gambar holistik yang dibentuk kata-kata, melaporkan pandangan informan secara terperinci, dan disusun dalam sebuah latar ilmiah.

Instrument utama dalam penelitian kualitatif adalah peneliti sendiri dengan berbagai media yang dapat dipergunakan sebagai alat bantu dalam pengumpulan informasi dan segala data yang dibutuhkan. Peneliti sebagai instrument utama penelitian dapat berperan sebagai perencana, pelaksana pengumpulan data, penafsir atau penganalisis data, dan penyusun laporan penelitian (Moleong, 2013:168).

Pemerolehan data yang lengkap menggunakan teknik yang relevan dengan tujuan yang ingin dicapai. Teknik yang dimaksud adalah observasi, wawancara, dan angket. penelitian ini dilaksanakan di Palippis pada tahun pelajaran 20192020

Bagan alir dari penelitian yang akan dilakasanakan selama 1 tahun dijabarkan secara detail pada ganbar 1 bawah ini: 


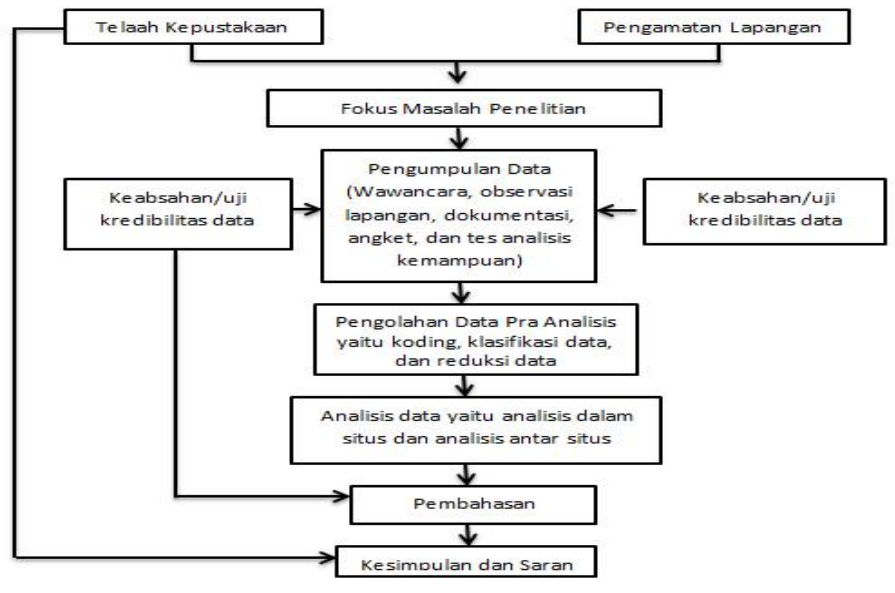

Gambar 1. Bagan Alur Penelitian

Sumber data utama dalam penelitian kualitatif ialah kata-kata selebihnya adalah data tambahan seperti dokumen dan lain-lain (Moleong dalam Oksinata, 2010). Sehubungan dalam penelitian ini, sumber data dari peneliti adalah:

1. Dokumen

Sumber data berupa dokumen dalam penelitian ini adalah buku antologi puisi esai berjudul "Mantra Laut Mandar" karya 5 (lima) penyair Sulawesi Barat yang diterbitkan pada Agustus 2018 oleh Cerah Budaya Indonesia. Buku ini memuat puisi esai "Aborsi di Palippis" karya Syuman Saeha yang merupakan data utama dari penelitian ini dan termuat pada halaman 95. Untuk menunjang kelengkapan penelitian ini digunakan buku-buku dan artikel-artikel dari internet yang berhubungan dengan penelitian ini.

2. Narasumber

Narasumber dalam penelitian ini adalah Syuman Saeha selaku penulis puisi esai "Aborsi di Palippis". Selain Syuman Saeha selaku narasumber utama pada penelitian ini, terdapat dua narasumber pendukung yaitu Keluarga Pua Kamal yang tinggal di pesisir pantai Palippis dan Ridwan Alimuddin selaku pemerhati linkungan di Sulawesi Barat. Narasumber berfungsi menambah data yang telah diperoleh.

3. Transkrip wawancara

Transkrip wawancara dalam penelitian ini berupa hasil wawancara peneliti kepada narasumber utama yakni Syuman Saeha dan keluarga Pua Kamal dan Ridwan Alimuddin selaku narasumber pendukung. Hasil wawancara yang terkemas pada transkrip wawancara memberikan informasi yang diperlukan terkait kritik sosial yang menyasar kepada pemerintah, kontraktor dan 
masyarakat. Informasi tersebut lebih membantu penulis untuk mendeskripsikan data yang tidak ditemukan dalam sumber data dokumen.

Analisis data adalah proses mencari dan menyusun secara sistematis data yang telah diperoleh. Analisis data kualitatif adalah bersifat induktif yaitu suatu analisis berdasarkan data yang diperoleh selnjutnya dikembangkan menjadi hipotesis (Sugiyono, 2017:245). Teknik analisis data yang dilakukan oleh peneliti adalah data dibaca, data ditandai, data dikelompokkan, data dianalisis, penyajian, dan menyimpulkan.

\section{HASIL PENELITIAN DAN PEMBAHASAN Kritik Sosial Terhadap Kontraktor}

Berdasarkan hasil analisis kritik sosial dalam puisi esai "Aborsi di Palippis karya Syuman Saeha, terdapat empat poin yang menjadi kritik sosial terhadap kontraktor diantaranya 1) Kritik terhadap upaya kontraktor agar proyek tetap dijalankan, 2) Kritik terhadap keserakahan pihak kontraktor dan 3) Kritik terhadap ketidakpedulian kontraktor terhadap lingkungan hidup sekitar pantai.

\section{1) Kritik terhadap upaya kontraktor agar proyek tetap dijalankan}

Syuman Saeha dalam puisi esainya yaitu "Aborsi di Palippis" cukup tegas menyampaikan kritiknya terhadap pihak kontraktor yang merupakan pelaksana dari kegiatan pembangunan tanggul beton ini. Sebagai eksekutor, kontraktor dalam puisi esai ini dijelaskan dengan segala upaya mengusahakan agar pembangunan tanggul beton terjadi.

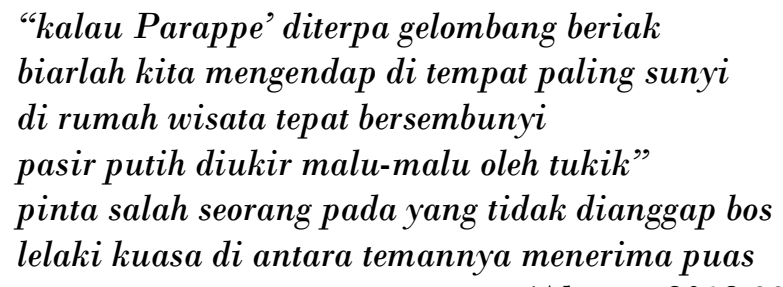

(Alimin, 2018:99)

Analisis penggalan puisi esai "Aborsi di Palippis" yang terletak di babak /1/ kesaksian seorang gadis ini menceritakan upaya yang selanjutnya akan dilakukan pihak kontraktor setelah menerima penolakan untuk melanjutkan pembangunan tanggul beton di Dusun Parappe' Desa Pambusuang. Penggunaan kata /di tempat paling sunyi/dan/di rumah wisata/ tentu merujuk kepada Pantai Palippis yang merupakan objek wisata yang mulai sepi dari pengunjung. Palippis ditunjuk sebagai target selanjutnya agar material pembangun tanggul beton yang sudah siap dikerjakan tidak sia sia. Begitulah penggambaran usaha kontraktor demi mencapai tujuannya. 


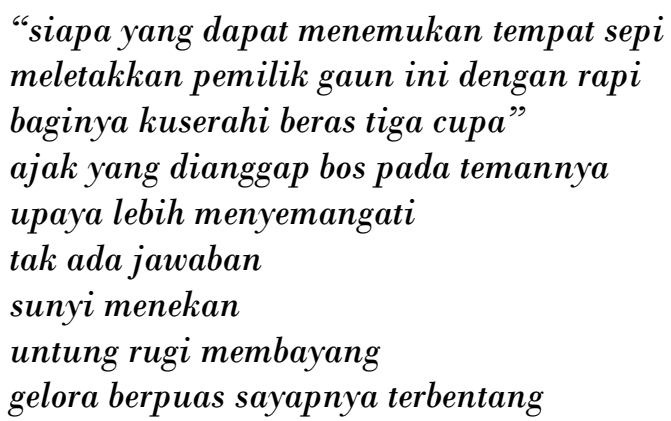

(Alimin, 2018:105-106)

Analisis data selanjutnya mengenai upaya konraktor demi melanjutkan pembangunan tanggul beton yang tertunda juga diungkapkan penyair pada bait ke 5 babak /6/ aborsi. Setelah di Palippis juga mengalami penolakan serupa Dusun Parappe Desa Pambusuang, para kontraktor tetap tidak gentar kepada niat awalnya. Diceritakan bahwa seseorang yang dianggap bos bahkan mengimingimingi imbalan berupa beras tiga cupa (liter atau gantang) kepada anak buahnya yang mampu menemukan lokasi pembangunan tanggul selanjutnya. Semua itu dilakukan semata-mata akibat untung rugi mulai mengancam pihak kontraktor.

Pada bait ke 15 di babak /6/ aborsi kembali penyair menggambarkan upaya kontraktor melanjutkan pembangunan tanggul sesuai penggalan puisi esai berikut.

"kalian harus dapat menemukan tempat yang cocok gadis itu sungguh tak diminati masyarakat nelayan apa salah kita dalam bertindak padahal semua amplop sudah terbagikan bangsat sialan" umpat lelaki yang dianggap bos itu pada temannya kerumunan itu hening seketika tiba-tiba satu dari mereka mengajukan pendapat ditunjuknya sebuah pantai dari arah barat lengkap keterangan luas panjang dan alamat dianggap hanya tempat perahu tidur pabila mengantuk "ketiga kali aku dipoles biar lebih cantik" aku gadis itu sambil bertolak ke arah barat

(Alimin, 2018:107)

Analisis puisi esai "Aborsi di Palippis" pada kutipan di atas mengungkap bahwa pihak kontraktor bahkan membagikan amplop demi memuluskan 
upayanya dalam membangun tangul beton. Namun yang terjadi justru sia sia belaka, menawarkan gadis (kata ganti dari tanggul) justru menghilangkan minat nelayan sepenuhnya. Pantang untuk gagal bagi kontraktor, mereka lalu menunjuk pantai dari arah barat sebagai lokasi selanjutnya material tanggul beton di bangun. Pantai yang dimaksud adalah Pantai Uwai Tawar yang terletak di Desa Tammangalle.

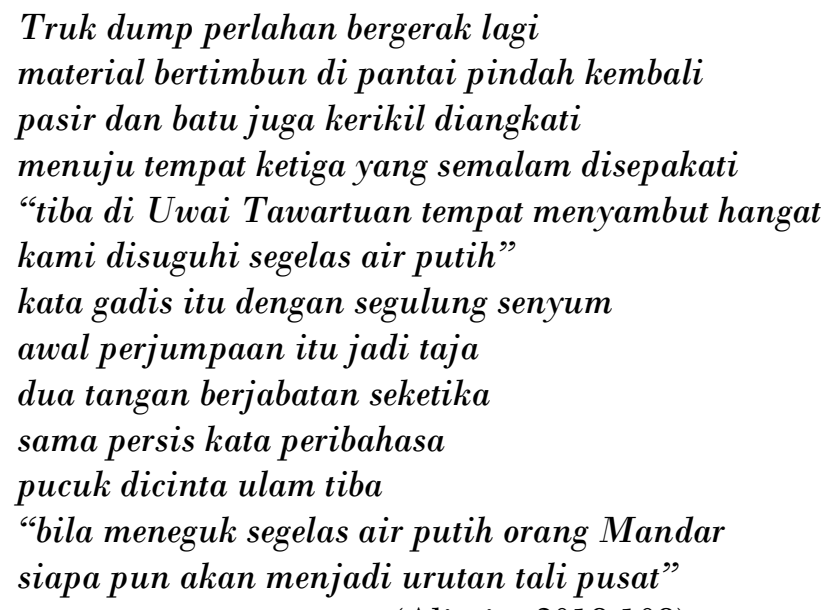

(Alimin, 2018:108)

Analisis kutipan puisi esai babak/7/ diarak ke arah senja bait ke 2 dan ke 3 di atas merupakan penjelasan mengenai bagaimana kesepakatan antara pihak kontraktor dan pihak masyarakat setempat sehingga pantai Uwai Tawar di Desa Tammangalle dipilih menjadi tempat pembangunan tanggul penahan ombak yang telah mengalami penolakan di Palippis. Dalam puisi esai "Aborsi di Palippis", peristiwa ini disimbolkan dengan salah satu pappasang pelluluareang (pesan leluhur tentang persaudaraan) yang terkenal di Mandar berbunyi "Мua" Mandundumi sakkaca uwai madingitta, milulluare'mitau iting tauo" (bila sudah minum air putih orang Mandar, maka bersaudaralah kau dengan orang tersebut) seperti termuat dalam salah satu catatan kaki puisi esai "Aborsi di Palippis" sebagai berikut.

Salah satu Pappasang Pelulluareang di Mandar, yang berbunyi, Мua' Mandundumi sakkaca uwai madingitta, milulluare'mi tau iting tauo.(Bila sudah minum air putih orang Mandar, maka bersaudaralah kau dengan orang tersebut). Dalam bahasa Mandar, pesan leluhur disebut pappasang. Sementara pelulluareang berarti persaudaraan. 


\section{2) Kritik terhadap keserakahan pihak kontraktor}

Dalam puisi esai "Aborsi di Palippis", penyair kerap menggambarkan pihak kontraktor sebagai pihak yang mengupayakan segalanya agar tujuannya tercapai dan menunjukkan keserakahannya terhadap materi. Seperti dalam kutipan puisi esai berikut.

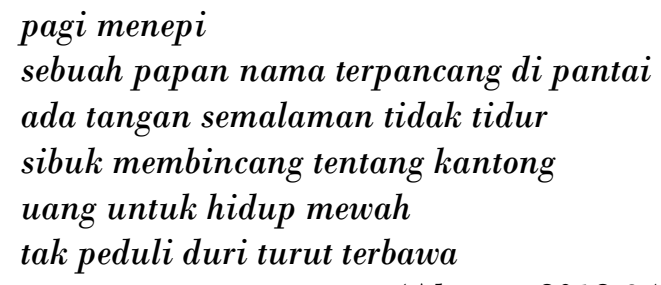

Analisis puisi esai "Aborsi di Palippis" memiliki prolog di babak /1/ dan bait di atas terdapat pada bait ke 5. Penggalan itu menceritakan tentang pemasangan papan proyek pembangunan tanggul di suatu malam tanpa diketahui oleh warga sekitar. Sifat keserakahan yang berarti selalu hendak memiliki lebih dari yang dimiliki tertuang dalam kalimat/sibuk membincang tentang kantong//uang untuk hidup mewah/. Maka dengan lahirnya harapan-harapan tersebut kontraktor akan mengupayakan dengan keras agar usahanya membangun tanggul beton tersebut bisa berhasil.

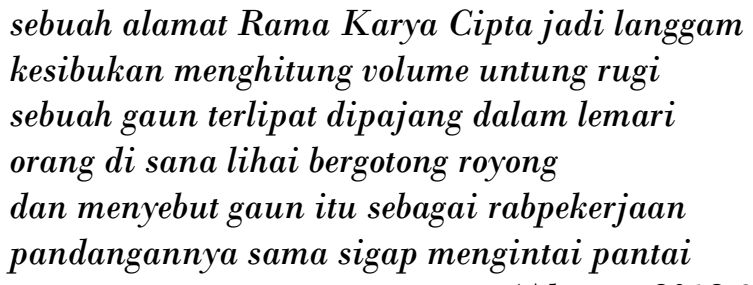

(Alimin, 2018:96)

Analisis data kutipan puisi esai ini merupakan lanjutan dari puisi esai di atas dan merupakan bait ke 6 di babak /1/ kesaksian seorang gadis. Kontraktor yang berada dibawah naungan perusahaan Rama Karya Cipta disebutkan oleh penyair di puisi esainya. Penyair menyebut /gaun/ sebagai metafora dari Rancangan Anggaran Biaya (RAB) yang merupakan kebutuhan utama demi berjalannya proyek ini. Tentu saja sebagai kontraktor yang punya dasar sebagai pebisnis maka untung rugi jadi pertimbangan yang besar padahal proyek belum dijalankan. 
"bila melihat gaunnya berbunga kembang pastilah tubuh di dalamnya sangat memuaskan kita akan sangat diuntungkan" kata seorang yang lebih berwibawa pada temannya tubuhnya bergetar dengan mata menyala

(Alimin, 2018:96)

Pernyataan hasil analisis dari kutipan puisi esai di atas dipertegas dengan lanjutan puisi esai di babak /1/ kesaksian seorang gadis di bait ke 7. Sekelompok kontraktor tengah membincang tentang gadis dan gaun miliknya yang bila dimanfaatkan sebaik mungkin akan membawa manfaat bagi mereka. Pernyataan ini diperkuat penyair lewat kalimat/kita akan sangat diuntungkan/ dan semua semata-mata hendak menemukan harapan akan materi berlebih.

3) Kritik Terhadap Ketidakpedulian Kontraktor Terhadap Lingkungan Hidup

\section{Sekitar Pantai}

Dengan harapan agar rencananya tercapai maka tiap penghalang tentu akan berusaha diatasi. Pekerjaan tanggul beton merupakan pekerjaan penuh risiko dan mengorbankan banyak hal termasuk masalah lingkungan hidup yang tidak akan lepas dari ekosistem pantai tempat tanggul beton akan dibangun. Seperti dalam kutipan puisi esai berikut.

truk dump puluhan membabi buta

bergerak mengangkut pasir

melaju membawa batu

bergontai sarat kerikil

alat berat ikut mencakar

di bawah ban pantai pecah dan terhambur

(Alimin, 2018:106)

Hasil analisis data yang terdapat pada bait ke 7 di babak /6/ aborsi, bait di atas menggambarkan suasana pantai yang semestinya indah justru dipenuhi oleh kehadiran puluhan truk dump tengah hilir mudik membawa material bangunan. Pemandangan pantai diperburuk dengan pasir putih Palippis yang terlindas truk dump. Penyair menggunakan kalimat /di bawah ban pantai pecah dan terhambur/. Tidak hanya merusak lingkungan pantai namun juga apa-apa saja yang tersembunyi di bawah pasir. Meskipun tanggul tidak jadi dibangun namun alat berat berupa ekskavator terlanjur membekas dan menginjak pasir putih Palippis. 


\title{
Kritik Sosial Kepada Masyarakat
}

Berdasarkan hasil analisis kritik sosial dalam puisi esai "Aborsi di Palippis karya Syuman Saeha, terdapat empat poin yang menjadi kritik sosial terhadap masyarakat diantaranya 1) Kritik terhadap ketidakpedulian masyarakat wisatawan atas sampah, 2) Kritik terhadap hilangnya rasa peduli terhadap pelestarian Palippis dan 3) Kritik terhadap kurangnya pengetahuan masyarakat terhadap pembangunan tanggul.

\section{1). Kritik terhadap ketidakpedulian masyarakat wisatawan atas sampah}

Sampah yang merupakan babak dari gaya hidup manusia telah menjadi tanggung jawab bersama. Namun terkadang hal yang cenderung sepele ini masih luput dari kesadaran. Bukan hanya tanggul, persoalan sampah di area pantai Palippis turut menjadi perhatian penyair seperti dalam babak /5/ mengitari tallo' bait ke 2 dan ke 3.

\author{
dari arah matahari terbenam \\ diantara kaktus berderet rombongan kambing \\ sampah di pantai berderit dipatuk kakinya yang runcing \\ tak ada pengaku sebagai pemilik bila lepas pagi hari \\ sampai malam benar larut masih berkeliaran \\ mereka mengeroyok rumput pantai di kaki tebing \\ begitu gundul sampah plastik tak urung dicangkangi
}

(Alimin, 2018:103)

Analisis data di atas mengungkapkan bahwa penyair kembali menggunakan perumpamaan. Kata /kambing/dipilih sebagai penganti kata/wisatawan/merujuk pada sikap para wisatawan yang dimaksud yang tidak bertanggung jawab atas sampah. Wisatawan yang ditunjuk datang dari Barat tersebut dikatakan bahkan hingga malam larut tetap acuh tak acuh atas keberadaan sampah yang tak kunjung dibuang ketempatnya. Orang-orang ini lupa bahwa sampah merupakan tanggung jawab bersama sebagai manusia.

\author{
di anggapnya Palippis sebagai buangan \\ pada tanah hampar campur pasir \\ desah nyiur sepanjang hari \\ tempat mata memberi peduli \\ sampah raksasa terbuang dengan bualan \\ menghampiri jarak sempit pada tebing \\ Bala rumah sampah yang anyir \\ "memasuki Palippis dengan sanggah
}


tak kenyang serakah menganga"

kata gadis itu

(Alimin, 2018:101)

Analisis data yang terdapat pada bait ke 3 dari babak /3/ sampah yang terbuang, berikut penyair mencoba menjelaskan mengenai Palippis yang dipenuhi oleh sampah sehingga menyebut Bala yang merupakan desa di mana Pantai Palippis terletak menjadi rumah sampah yang anyir. Selain sampah yang dibawa oleh wisatawan, Palippis juga kedatangan sampah kiriman dari laut. Hingga kini sampah masih menjadi salah satu masalah yang belum selesai di Palippis sesuai kutipan wawancara sebaga berikut.

Persoalan sampah ini yang masih jadi masalah. Karena memang kami tinggal di sini mau tidak mau meski bukan sampah kami maka kami yang membersihkan. Tidak ada kesadaran pada orang orang yang datang. Sampah juga letaknya banyak di sana di dekat pantai. Itu di sana jadi tempat pembuangan. Sumber: Wawancara dengan warga pantai Palippis

\section{2). Kritik terhadap hilangnya rasa peduli terhadap pelestarian Palippis}

Pelestarian Palippis sebagai pantai yang memiliki nilai-nilai luhur tertentu dan yang terbaru sebagai objek wisata juga merupakan tanggung jawab bersama.Hanya saja seiring berlalunya waktu Palippis mengalami perubahan seperti yang disebutkan penyair dalam puisi esainya sebagai berikut.

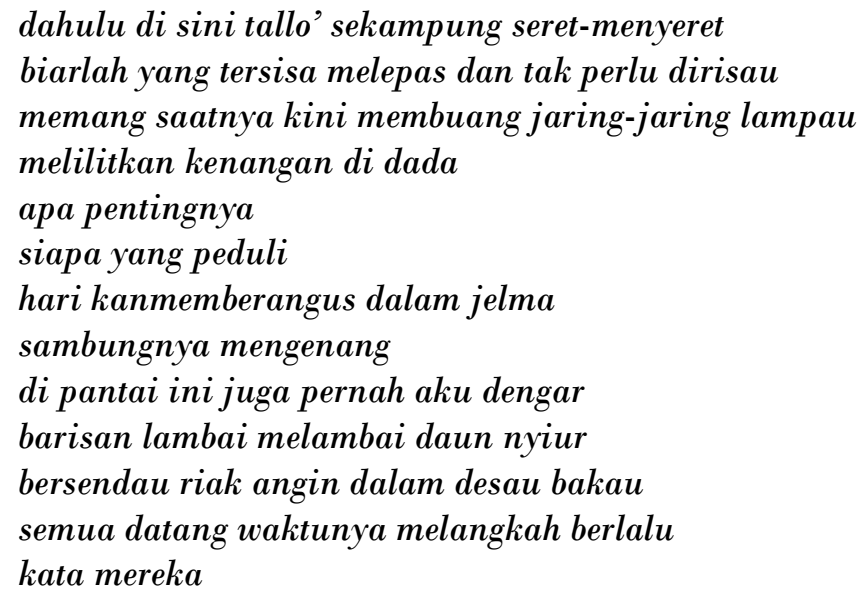

(Alimin, 2018:102)

Analisis data kutipan puisi esai yang ada di babak /4/ menyapa tangguldi bait ke 3 dan 4 ini penyair mencoba menjelaskan tentang bagaimana suasana Pantai Palippis dulunya. Selain dikenal sebagai pantai yang memiliki pasir putih, 
penduduk setempat mengenalnya dengan sebutan kappungtallo'. Namun itu dulu, bagi penyair kini /apa pentingnya/ /siapa yang peduli/ pada nasib Palippis. Selain tallo'yang tidak sebanyak dulu, penyair mengenang Palippis sebagai pantai yang punya banyak pohon kelapa. /semua datang waktunya melangkah berlalu/, bahwa segala kelestarian Palippis ini dimaksud penyair telah menjadi babak dari masa lalu, semenjak pudarnya rasa peduli.

\section{3) Kritik Terhadap Kurangnya Pengetahuan Masyarakat Terhadap Pembangunan Tanggul}

Ancaman abrasi pantai menghantui masyarakat pesisir pantai Palippis. Lantas pemerintah menawarkan membangun tanggul beton sebagai solusi atas masalah tersebut dan segelintir masyarakat menerima usulan tersebut begitu saja. Dalam puisi esai "Aborsi di Palippis" disebutkan penjelasan pihak kontrakor sebagai berikut.
"orang-orang di sana sering berkata"
ujar gadis itu menunjuk yang dipertuan
"kalau pantai ini tak dibekukan
ombak akan mencium bau lumut tebing
pasir terendam dalam derit
hari-harinya melayani kelam

(Alimin, 2018:101)

Analisis data kutipan puisi esai yang terdapat di babak /4/ menyapa tanggul bait pertama dan kedua ini berisi penjelasan pihak kontraktor kepada masyarakat bahwa tanggul mampu menahan ombak yang mengancam pemukiman dan tebing di tepi pantai. Namun itu semua tanpa mempertimbangkan sisi lain jika tanggul benar-benar di bangun, apalagi jenis tanggul yang akan digunakan adalah tanggul beton yang tidak ramah lingkungan dan amat mengancam keberlangsungan ekosistem penyu.

Tema-tema dalam puisi esai secara keseluruhan didapatkan penyair dari kehidupan masyarakat. Hal ini memberi petunjukhubungan yang dekat antara penulis dan pembaca sebab keduanya merupakan anggota masyarakat.Bahasa dalam puisi esai merupakan sarana bagi penulis untuk berkomunikasi dengan masyarakat pembacanya dalam menyampaikan tema. Tema yang terdapat pada puisi esai "Aborsi di Palippis" adalah mengenai dampak buruk dari proyek pemerintah yakni pembangunan tanggul yang dikerjakan secara asal-asalan. Untuk itu penyair tengah berusaha menyampaikan amanat agar kiranya pembaca terketuk nuraninya untuk tidak berbuat yang mendukung tindakan para sasaran 
kritik dalam puisi esai ini. Bahwa sastra pada umumnya ditulis pengarangnya untuk memperbaiki atau mengkritisi lingkungan agar semakin baik.

Menyikapi apa yang terjadi di Palippis, penyair Syuman Saeha menulis puisi esai "Aborsi di Palippis" sebagai bentuk kritiknya terhadap rencana pembangunan tanggul sebagaimana kritik sosial dalam karya sastra menjadi sarana bagi pengarang untuk menyampaikan ketidakpuasannya terhadap sendisendi kehidupan masyarakat. Merujuk pada hasil wawancara peneliti dengan narasumber yaitu Syuman Saeha maka penyair mengungkapkan alasannya mengumpakan tanggul sebagai seorang gadis karena kontroversi pembangunan tanggul membuat pembicaraan mengenai tanggul menjadi menarik selayaknya pembicaraan mengenai para gadis. Pemaksaan agar proyek tanggul tetap berjalan dianggap penyair tidak lebih seperti perkosaan yang dialami oleh para gadis. Lebih lanjut penyair menuturkan proyek tanggul lagi-lagi jadi perhatian oleh sebab memiliki Rancangan Anggaran Biaya (RAB) sebagaimana para gadis yang berusaha tampil menarik dengan pakaian atau gaun yang mereka kenakan.

Sementara perumpamaan aborsi dianggap penyair sebagai kegiatan membuang sebagaimana proyek tanggul di Palippis merupakan proyek buangan yang ditolak pembangunannya di Dusun Parappe Desa Pambusuang. Kontraktor sebagai pebisnis tentu tidak ingin menelan kerugian dari ancaman gagalnya rencana sebuah pembangunan proyek. Pada puisi esai "Aborsi di Palippis" beberapa kali penyair menekankan bahwa kontraktor berupaya keras agar material yang ditolak pengerjaannya di Dusun Parappe Desa Pambusuang dapat dibangun dengan berpindah tempat bahkan seringkali penyair menyebut kontraktor sangat serakah demi mencapai tujuannya dan tidak lagi peduli pada pelestarian terutama penyu.

Terhadap masyarakat yang cenderung apatis terhadap lingkungan sekitarnya ikut menjadi sasaran kritik sosial penyair pada puisi esai "Aborsi di Palippis". Selain kepada persoalan sampah yang telah menjadi babak klasik dari kehidupan bermasyarakat, masyarakat yang setuju terhadap rencana pembangunan tanggul pun dikatakan telah menerima sesuatu berupa amplop pertanda masyarakat kurang memahami dampak buruk jangka panjang yang dapat terjadi jika tanggul penahan ombak di pantai Palippis benar-benar dibangun.

Karya ini menjadi potret bagaimana rencana pembangunan tanggul beton dibarengi usaha para kontraktor dalam membangun tanggul di pantai Palippis mendapat penolakan dari masyarakat nelayan setempat. Selain penolakan oleh nelayan, pembangunan tanggul Palippis yang kala itu ramai diperbincangkan di media sosial juga mendapat tentangan keras dari berbagai pihak seperti pemerhati budaya dan lingkungan, bahwa dibalik yang tidak peduli masih ada segelintir yang peduli. Bagi peneliti, puisi esai "Aborsi di Palippis" karya Syuman Saeha telah memenuhi fungsi sastra sebagai fungsi didaktif dan fungsi moralitas. Sebagai 
didaktif, "Aborsi di Palippis" telah mengarahkan peneliti betapa kesadaran atas pelestarian lingkungan pantai Palippis, pelestarian ekosistem penyu maupun perahu sande'itu amatlah penting. Moralitas yang ditampilkan akan membuat pembaca tidak menyetujui sifat para kontraktor terutama keserakahan yang ditunjukkan dalam penggalan puisi esai ini.

\section{SIMPULAN}

Kritik sosial yang pedas juga diarahkan penyair ke pihak kontraktor atas usaha upaya kontraktor agar proyek tanggul tetap berjalan. Kritik pun diarahkan ke sifat serakah para kontraktor dan ketidakpedulian kontraktor terhadap pelestarian lingkungan dan ekosistem sekitar pantai Palippis. Kritik sosial terhadap pihak masyarakat disoroti dari bagaimana masyarakat abai terhadap persoalan sampah juga hilangnya rasa peduli merawat kelestarian Palippis. Lalu kritik terakhir ditujukan kepada masyarakat yang kurang memahami tentang arah pembangunan tanggul di Palippis.

\section{DAFTAR PUSTAKA}

Alimin, Adi Arwan,Dkk. 2018. Mantra Laut Mandar. Sulawesi Barat: Cerah Budaya Indonesia.

Alimuddin, Ridwan. 2019. Kebijakan Tak Berbasis Budaya Bahari. [pdf]. http://slideshare.net/mobile/ridwanmandar/kebijakan-tak-berbasis-budayabahari-142243200 (Diakses 23 April 2019).

Amalia, Arifiani. 2006. Kritik Sosial Dalam Kumpulan Cerpen Dunia Sukab karya Seno Gumira Ajidarma. Skripsi, Jurusan Sastra Indonesia, Fakultas Sastra, Universitas Negeri Malang

Creswell, J. 2007. Qualitative Inquiry \& Research Design: Choosing Among Five Approaches, 2nd ed. California : Sage Publication.

Darmayanti, Ida Ayu Made. 2012. Seksualitas Perempuan Bali Dalam Hegemoni Kasta: Kajian Kritik Sastra Feminis Pada Dua Novel Karangan Oka Rusmini.

https://ejournal.undiksha.ac.id/index.php/JISH/article/view/4472/3445. Ejurnal Vol. 3, No. 2, Oktober.

Moleong, Lexy J. 2013. Metode Penelitian Kualitatif. Edisi Revisi. Bandung : PT. Remaja Rosdakarya.

Pratiwi, Dkk. 2017. Kritik Sosial Dalam Kumpulan Puisi W.S Rendra: Kehidupan Masyarakat di Indonesia. file:///C:/Users/ASUS/Downloads/874-2243-1SM.pdf. Malang: Pendidikan Bahasa dan Sastra Indonesia, Fakultas Keguruan dan Ilmu Pendidikan, Universitas Muhammadiyah Malang Rizka Willya. 2017. Perempuan Dalam Cerpen "Sarung Ayah" Karya Fira Basuki: 
http://scholar.unand.ac.id/27868/1/COVER\%20N\%20ABSTRAK.pdf. Padang: Fakultas Ilmu Budaya Universitas Andalas.

Sugiyono. 2017. Metode Penelitian Kuantitatif, Kualitatif dan R \& D. Bandung. Penerbit Alfabeta. 